\title{
LETTER
}

\section{Bedside handover of critically ill patients}

\author{
Matt P Wise*1, Matt P Morgan², Christopher D Hingston' and Helen L Watkins' \\ See related viewpoint by Cohen et al., http://ccforum.com/content/16/1/303
}

Cohen and colleagues' recent viewpoint emphasised that handover is not a unilateral transfer of information and that when poorly conducted it can degrade quality of care [1]. A key feature of handover required by clinicians is the big picture, which shapes the viewpoint of the receiving party [1]. Frequently this is obscured in critically ill patients by a surfeit of physiological variables or results, and this 'noise' denigrates the handover process. Such a scenario is often observed with less experienced clinicians, who are also the most frequently studied group. Only one investigation has described handover by experienced full-time faculty physicians in critical care [2]. Unsurprisingly, handover between these individuals did not conform to widely promoted communication schemes but did commonly include questions allowing two physicians to jointly construct a picture of the patient.

Our institution operates a unique staffing model for the United Kingdom, with a resident senior clinician (consultant) shift pattern [3]. Handover is performed on 19 occasions throughout the week (three times on weekdays and twice daily at weekends) and is undertaken by the senior clinician. In contrast to how handover is performed in most institutions [2], this occurs at the bedside twice daily. Although not without challenges (including respecting the patient's dignity), performing handover at the bedside has several advantages - which include promoting a two-way dialogue between handover provider and recipient, and, most importantly, a visual reference of the patient between individuals participating in the transfer of care. This model of handover was also found to be more effective in other emergency settings [4].

\section{Competing interests}

The authors declare that they have no competing interests.

\section{Author details}

'Department of Critical Care, University Hospital of Wales, Cardiff CF14 4XW

UK. ${ }^{2}$ Department of Anaesthesia, University Hospital of Wales, Cardiff CF14 4XW, UK.

Published: 23 March 2012

\section{References}

1. Cohen MD, Hilligoss B, Kajdacsy-Balla Amaral AC: A handoff is not a telegram: an understanding of the patient is co-constructed. Crit Care 2012, 16:303.

2. Ilan R, Lebaron CD, Christianson MK, Heyland DK, Day A, Cohen MD: Handover patterns: an observational study of critical care physicians. BMC Health Serv Res 2012, 12:11.

3. Frost $P$, Wise M: Resident consultants in large intensive care units? Crit Care Resusc 2006, 8:50-51.

4. Richmond C, Merrick E, Green T, Dinh M, ledema R: Bedside review of patient care in an emergency department: the cow round. Emerg Med Australas 2011, 23:600-605.

doi:10.1186/cc11245

Cite this article as: Wise MP, et al:: Bedside handover of critically ill patients. Critical Care 2012, 16:419.
*Correspondence: mattwise@doctors.org.uk

'Department of Critical Care, University Hospital of Wales, Cardiff CF14 4XW, UK

Full list of author information is available at the end of the article 